bioRxiv preprint doi: https://doi.org/10.1101/2022.02.28.481849; this version posted March 3, 2022. The copyright holder for this preprint

(which was not certified by peer review) is the author/funder, who has granted bioRxiv a license to display the preprint in perpetuity. It is made available under aCC-BY-NC-ND 4.0 International license.

\title{
Aging the Brain: Multi-Region Methylation Principal Component Based Clock in the Context of
}

\author{
Alzheimer's Disease \\ Kyra L. Thrush ${ }^{1}$, David A. Bennett ${ }^{2}$, Christopher Gaiteri ${ }^{2}$, Steve Horvath ${ }^{3,4}$, Christopher H. van Dyck ${ }^{5,6}$, Albert T. Higgins-Chen ${ }^{5,7}$, \\ Morgan E. Levine ${ }^{1,8}$ \\ ${ }^{1}$ Program in Computational Biology and Bioinformatics, Yale University, New Haven, CT, USA \\ ${ }^{2}$ Rush Alzheimer's Disease Center, Rush University Medical Center, Chicago, IL, USA \\ ${ }^{3}$ Department of Human Genetics, David Geffen School of Medicine, University of California Los Angeles (UCLA), Los Angeles, CA, \\ 90095, USA \\ ${ }^{4}$ Department of Biostatistics, Fielding School of Public Health, UCLA, Los Angeles, CA, USA \\ ${ }^{5}$ Department of Psychiatry, Yale University School of Medicine, New Haven, CT, USA \\ ${ }^{6}$ Alzheimer's Disease Research Center, Yale University School of Medicine, New Haven, CT, USA \\ ${ }^{7}$ VA Connecticut Healthcare System, West Haven, CT, USA \\ ${ }^{8}$ Department of Pathology, Yale University School of Medicine, New Haven, CT, USA \\ Keywords (5): Epigenetic Clocks, Alzheimer's Disease, Brain, Unsupervised Machine Learning, Age Acceleration
}

\begin{abstract}
Alzheimer's disease (AD) risk increases exponentially with age and is associated with multiple molecular hallmarks of aging, one of which is epigenetic alterations. Epigenetic age predictors based on 5' cytosine methylation (DNAm) have previously suggested that biological age acceleration may occur in AD brain tissue. To further investigate brain epigenetic aging in $\mathrm{AD}$, we generated a novel age predictor termed PCBrainAge that was trained solely in cortical samples. This predictor utilizes a combination of principal components analysis and regularized regression, which reduces technical noise and greatly improves test-retest reliability. For further testing, we generated DNAm data from multiple brain regions in a sample from the Religious Orders Study and Rush Memory \& Aging Project. PCBrainAge captures meaningful heterogeneity of aging, calculated according to an individual's age acceleration beyond expectation. Its acceleration demonstrates stronger associations with clinical $\mathrm{AD}$ dementia, pathologic $\mathrm{AD}$, and $\mathrm{APOE} \varepsilon 4$ carrier status compared to extant epigenetic age predictors. It does so across multiple cortical and subcortical regions. Overall, PCBrainAge is useful for investigating heterogeneity in brain aging, as well as epigenetic alterations underlying AD risk and resilience.
\end{abstract}


bioRxiv preprint doi: https://doi.org/10.1101/2022.02.28.481849; this version posted March 3, 2022. The copyright holder for this preprint (which was not certified by peer review) is the author/funder, who has granted bioRxiv a license to display the preprint in perpetuity. It is made available under aCC-BY-NC-ND 4.0 International license.

\section{Introduction}

Aging is the most significant and consistently demonstrated risk factor for Alzheimer's disease (AD) $[1,2]$. As a result, the aging of the U.S. population is expected to coincide with a rise in AD cases, increasing from 5.8 million in 2020, to 13.8 million projected by 2050 [3]. Chronological age, defined as time since birth, is a nonmodifiable risk factor. Biological aging however, or the molecular and cellular changes that underlie the process of aging, may be malleable [4-6]. Approaching the challenge of AD prevention and treatment through the lens of biological aging thus provides a major opportunity for improving cognitive health and reducing disease burden.

Because the brain is the central site for AD pathology, understanding the specific aging of this tissue is a priority. As brain tissue ages, misfolded tau and amyloid proteins accumulate due to a loss of proteostasis, one molecular hallmark of aging [7]. While this occurs in older adults with normal cognition or mild cognitive impairment, it is generally more pronounced in subjects with AD dementia [8-10]. Neuritic plaque and neurofibrillary tangles form the basis for the neuropathological diagnosis of AD [11]. Further, more rapid accumulation of tau [12] and $\beta$-amyloid [13] aggregates is also linked to inheritance of the APOE $\varepsilon 4$ allele, which is itself linked to a number of age-related outcomes, including increased AD dementia risk [14], CVD risk [15,16], and reduced lifespan $[17,18]$. This suggests that while AD may not be a normal part of aging, it is partially driven by changes that are known to relate to basic aging processes.

Additional hallmarks of biological aging, which include epigenetic alterations $[19,20]$, have also been implicated in the pathology of AD. For instance, 5' cytosine methylation (DNAm) differences have been shown to track aging and can be quantitatively combined to produce composite aging biomarkers, termed "epigenetic clocks" [21]. We and others have shown that the divergence between observed and predicted ages produced by epigenetic clocks relate to AD pathology. For instance, Horvath pan-tissue [22] and Levine PhenoAge [23] epigenetic age acceleration correlate with abnormally high neuritic plaque, NFT, and $\beta$-amyloid loads. While this provides further molecular evidence of a link between AD risk and aging, such clocks are typically developed in peripheral tissues and may not capture the unique aging changes in the brain. A notable exception is the recent

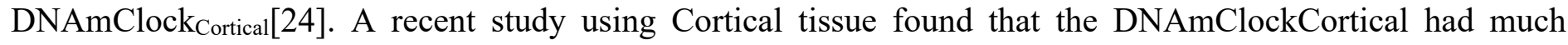
stronger associations with AD clinical and neuropathologic traits relative to Horvath, Hannum and PhenoAge 
clocks based on non-neuronal tissues [25]. Building on previous work, our study incorporates two additional novel features. First, we sought to investigate the extent to which the uneven pathological burden evident by amyloid [26] and tau [27] staging is captured when considering DNAm across multiple paired brain regions, rather than in singular areas of the cortex or hippocampus. Second, we have previously shown that CpG clocks often suffer from significant technical noise, hindering their applications. Therefore, we sought to use our recently developed approach to improve signal-to-noise ratios in methylation data, leading to improved reliability and construct validity in our novel epigenetic clock [28].

Overall, we hypothesized that a brain age methylation-based predictor could be developed with meaningful disease associations and broad multi-brain-region utility. To test this, we used DNAm capture to generate a PC-based epigenetic predictor of brain aging which we show to: (1) strongly reflect AD neuropathology and cognitive decline, and (2) track age across multiple brain regions. This resulting measure, PCBrainAge, is applicable for use in existing brain and tissue banks, and many publicly available postmortem datasets for the study of AD.

\section{Results}

\section{Model Design \& Testing}

To generate a predictor of aging in the brain, we selected a publicly accessible dataset deposited into the Gene Expression Omnibus [29] (GSE74193) [30]. In brief, this dataset contains methylation data from dorsolateral prefrontal cortex (DLPFC) of 399 individuals aged 20+ (see Methods for further details). This dataset includes patients diagnosed with schizophrenia $(n=187 ; 47 \%)$. However, this neuropsychiatric disease has not been shown to be robustly associated with epigenetic signatures of chronological age in either blood or brain, despite acceleration in clocks predicting mortality in blood [31,32]. Our model's outcome variable is chronological age, so inclusion of schizophrenia samples is reasonable and potentially advantageous: Inclusion of schizophrenia samples reduces the likelihood that general brain pathology will exert a large impact on the model's predictions, as the model is forced to predict chronological age despite schizophrenia status. Nevertheless, as a sensitivity analysis, we also trained a model using only control individuals, which did not 
bioRxiv preprint doi: https://doi.org/10.1101/2022.02.28.481849; this version posted March 3, 2022. The copyright holder for this preprint (which was not certified by peer review) is the author/funder, who has granted bioRxiv a license to display the preprint in perpetuity. It is made available under aCC-BY-NC-ND 4.0 International license.

improve results (Figure S1). Thus, we included all high-quality samples for training, regardless of schizophrenia status.

The training method to generate our predictor is built upon our recently published PC Clock method [28]. In brief, singular vector decomposition (SVD), an extension of principal components analysis suitable for wide format data (i.e. where features outnumber samples), was performed on this training methylation dataset. This analysis was limited to $\mathrm{CpG}$ sites that are overlapped between the training, test, and validation datasets collected on $450 \mathrm{~K}$ or EPIC arrays (see Methods for more detail). This produced 399 left singular vectors, which for general purposes, are referred to here as principal components (PCs) of 5'-cystosine methylation in postmortem dorsolateral prefrontal cortex (DLPFC). The PC scores, representing an individual's projection values onto the principal component vectors, were used as the set of variables from which age was predicted via elastic net penalized regression.

To predict training sample age, three models were generated, differing in the sex representation of subjects. This choice was based upon known sex specific differences in aging [33], and evidence of sex-specific differences in AD risk and AD neurobiology [34], and. All models used elastic net penalized regression in the appropriate individuals to find the optimal weighted linear average of PCs to predict chronological age; the first utilized both sexes $(n=399$, Figure 1A,D); the second was fit to only males $(n=262$, Figure $1 B, E)$; the third was fit to only females $(n=137$, Figure $1 C, F)$. Regardless of the sample used for training, we found that each model attained similar correlation between predicted and chronological age in both males and females. Male- and female-specific age correlations for each model can be found in Table 1.

A total of 195 of 399 PCs were selected for use in one or more models, with the female model (PCBrainAge.F) selecting the fewest variables. However, a completely overlapped set of 15 PCs (referred to as the core PCs) were selected for all three models, representing an important centralized signal of aging (Figure $1 \mathrm{G})$. The creation of three degenerate models in this manner allowed us to isolate a robust brain aging signal. We investigated whether these core PCs were significantly more important than their non-core counterparts in each model. To do so, we sequestered the 15 core PCs in the training data, as well as 3 different sets of non-core PCs corresponding to each original model. Using the same elastic net regression procedure as the original models, we 
bioRxiv preprint doi: https://doi.org/10.1101/2022.02.28.481849; this version posted March 3, 2022. The copyright holder for this preprint

(which was not certified by peer review) is the author/funder, who has granted bioRxiv a license to display the preprint in perpetuity. It is made available under aCC-BY-NC-ND 4.0 International license.

regressed the core and noncore PC scores to age in the appropriate training subcohorts. The 15 core principal components were sufficient to predict age in the training data. However, the non-core models were unable to successfully do so (Figure S2). Therefore, we generated a final model PCBrainAge.C. This was trained in both males and females and includes only the 15 core PCs (Figure 1H). As the core PC version of PCBrainAge is the overall superior model—both requiring limited information and performing best—only this model is used hereafter and will be simply referred to as PCBrainAge for clarity.

To validate models of aging generated from training data, an independent methylation dataset of 718 DLPFC samples was obtained through Synapse (syn5850422) [35]. All datasets used in the current work are characterized in Table S1. Estimation of the individuals' PC loadings was performed by projection onto the right singular vectors of the training dataset, thereby generating the 399 training PC vectors based upon the original eigenvalue estimations from the training data [28]. In terms of age predictions, PCBrainAge.C performs at least as well as all original sex-stratified and full models in the test dataset (Figure 1I), despite using fewer principal components.

Principal components are complex, composite variables, making them challenging to interpret. To investigate the information captured in the 15 core PCs, we correlated each PC to annotated features of the training dataset. This demonstrated that the largest source of variation in the data, as captured by PC1, is cell composition (Figure 2A). PC5 is most strongly correlated with age $(|\mathrm{r}|=0.68)$, with all PCs having a range of absolute biweight midcorrelation of $0.04-0.68$. As the overall model has correlation with age of 0.95 , the signal for chronological age is clearly distributed across PCs. PC8 and PC15 are related to biological sex. These observations were confirmed when the PCs were projected onto the test data (Figure 2B). While neuron proportion demonstrates correlations with more PCs in the test data compared to training data, there are several explanations for this observation. First, it is consistent with an expected, subtle loss of the imposed orthogonality when principal components are projected into new datasets. Second, our test dataset is comprised of only older adults, many with $\mathrm{AD}$, who are expected to have age-associated neuron loss. This may enhance correlations between cell composition and methylation PCs that were not otherwise apparent in training data capturing the entire lifespan. Third, the proportion of neurons in test data, unlike training data, is estimated using the methylation itself. 
Therefore, this estimated cell proportion may be doubly affected by disease states or other signals being captured in the data. Finally, in the test dataset, where some individuals have AD and dementia, we find that no single PC is highly and/or consistently correlated to AD status (Table S2).

We checked for relative agreement between training and testing data composition prior to applying PCBrainAge to test data. We previously showed that it is possible to use PCs from one dataset to generate reliable and useful PCs when projecting to another [28]. However, there can be differences in the distributions of PC scores: Therefore, we analyzed the distribution of PC scores from the core and found that while there are shifts in the mean, the general shape remains intact (Figure 2C,D). This can contribute to differences in the intercept in new datasets, a known behavior in common $\mathrm{CpG}$ clocks. However, this is easily corrected by using age acceleration, which does not consider intercept, for further analyses.

\section{PCBrainAge Correlates with Alzheimer's Pathology in DLPFC}

We calculated brain age acceleration in the ROSMAP DLPFC test dataset $(n=700)$ by generating linear models to regress PCBrainAge on samples' true ages at death and proportion of neurons (Table S3). Proportion of neurons was explicitly included to obtain residuals, as we hypothesized that cell proportion changes appear to be the dominant signal in data (Figure 2A, B). Ultimately, we are interested in whether PCBrainAge is predictive of $\mathrm{AD}$ beyond the well-characterized impacts of changes to neuron abundance. This is also consistent with previous reports that correcting for cell type heterogeneity improves mortality and biological age prediction [36,37]. Age acceleration was correlated with pathological and phenotypic traits known to indicate or affect the course of AD. To ensure that such correlations were not impacted by a nonlinear relationship of age and PCBrainAge, we verified a uniform distribution of residuals in both sexes (Figure 3A). Slight nonlinearity at the extremes of the distribution appeared to be the result of reduced sample density rather than true nonlinearity.

PCBrainAge accelerations were tested for association with AD clinical and pathologic diagnosis, and APOE $\varepsilon 4$ status. Postmortem binarized AD diagnosis according to neuritic plaque derived CERAD scores is significantly associated with accelerated brain aging (Figure 3B), as well as neurofibrillary tangle (NFT) derived Braak Staging (Figure 3C). Notably, PCBrainAge is significantly accelerated when AD is in the neocortical, final stages versus all prior stages, but has no discriminatory power between the entorhinal and limbic phases. This 
bioRxiv preprint doi: https://doi.org/10.1101/2022.02.28.481849; this version posted March 3, 2022. The copyright holder for this preprint

(which was not certified by peer review) is the author/funder, who has granted bioRxiv a license to display the preprint in perpetuity. It is made available under aCC-BY-NC-ND 4.0 International license.

likely reflects that PCBrainAge's training and testing are occurring in DLPFC, a neocortical region. PCBrainAge acceleration is also positively associated with post-mortem neuropathologic AD diagnosis by combined neuritic plaque (np) and NFT to derive NIA Reagan score (Figure 3D), as well as ante-mortem clinical diagnosis of AD dementia (Figure 3E). Those with the clinical diagnosis of mild cognitive impairment (MCI) are indistinguishable from non-cognitively impaired individuals. Thus, individuals with AD show greater PCBrainAge acceleration than their counterparts. The APOE $\varepsilon 4$ allele has been reproducibly associated with AD risk, and earlier onset of the disease [38]. Positive APOE $\varepsilon 4$ status (i.e. carrying 1 or 2 APOE $\varepsilon 4$ alleles) was significantly associated with PCBrainAge acceleration (Figure 3F). In fact, PCBrainAge is accelerated across APOE $\varepsilon 4$ carriers such that cognitively normal and $\mathrm{AD}$ confirmed individuals are indistinguishable. In contrast, among non-carriers those with AD show significant acceleration over premortem cognitively normal individuals (Figure 3G).

During the course of the current research, another methylation-based epigenetic clock was reported,

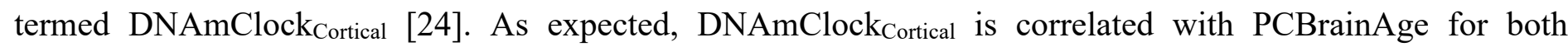
predicted age and age acceleration $(r=0.79$ and $r=0.56$, respectively) (Figure 4A, B). The training samples of DNAmClock Cortical $_{(n=1,047)}$ included the samples used to train PCBrainAge $(n=399)$ and was intended to accurately estimate chronological age of samples at all ages (training and test samples aged 1-108). Indeed,

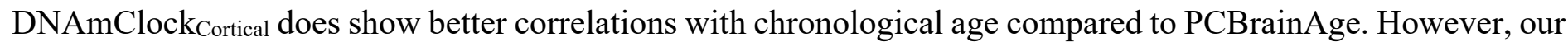
work with PCBrainAge intends to not only predict age, but to capture relevant biological heterogeneity of aging

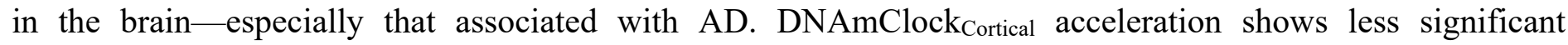
associations with AD clinical and pathologic phenotypes, and APOE $\varepsilon 4$ carrier status in comparison with

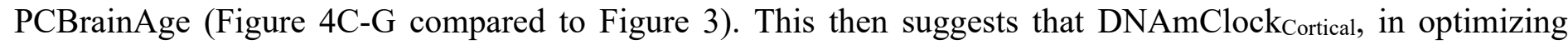
prediction of chronological age, may miss relevant heterogeneity and aging signals associated with AD. A 1-SD


amyloid and neuritic plaques. However, a 1-SD difference in PCBrainAge reflects greater differences with AD pathology, and is more balanced across various postmortem metrics of AD pathology (Figure 4H). Further, it was found that increasing standard deviations of PCBrainAge acceleration show monotonic increases in the

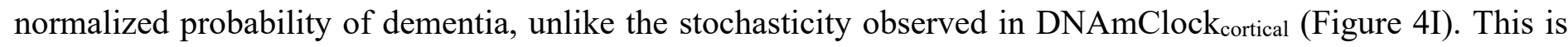


likely reflective of the hypothesized reduction in noisy $\mathrm{CpGs}$ and improved resolution expected to arise from using our PC Clocks method.

The association of PCBrainAge acceleration and AD pathology suggests a discriminatory role for PCBrainAge beyond age prediction itself. Increased prediction accuracy of chronological age may reduce the association with AD. PCBrainAge provides meaningful, nonrandom information about both age and the disease status of the brain.

Alzheimer's Pathology Correlates with PCBrainAge Across Multiple Brain Regions

Aging may have distinct effects on different brain regions with respect to atrophy, dendritic morphology, synaptic plasticity, and vasculature [39]. This may be reflected in epigenetic clocks, which indicate measurable differences in brain aging rates between regions [40]. The typical progression of AD involves the reproducible, staged invasion of neurofibrillary tangles [27] and amyloid- $\beta$ aggregations [26] through the brain. Though AD progression can be variable, some regions show amyloid or tau pathology earlier than others [41]. It is unknown whether regional differences in epigenetic age might help explain the differential impact of AD pathology amongst brain regions.

We used PCBrainAge to measure the aging trends across multiple brain regions and evaluate regionspecific associations with AD. Using 333 individuals' samples from an APOE $\varepsilon 4$ carrier enriched subcohort of ROSMAP (Table S1), we generated novel DNAm data from 3 distinct brain regions for each individual: Prefrontal cortex (PFC), Striatum (ST), and Cerebellum (CBM). This incorporated 212 overlapped individuals for which DNAm data for DLPFC (a distinct region and tissue slice) was available in the original test dataset used here. As done for the original test dataset, principal components were projected into this data, followed by PCBrainAge prediction for each independent region and sample. To account for repeated measurements and to improve modeling of epigenetic age acceleration, we employed a linear mixed effects (LME) model to utilize data across regions in tandem. The model is described in equation 1. The three brain regions tested here are expected to diverge in their epigenetic age prediction based upon data in prior clocks [42-44]. Therefore, we allowed a random effect to the model intercept with age according to brain region. Comparison of this model and simple regression is shown in Table S4. 
bioRxiv preprint doi: https://doi.org/10.1101/2022.02.28.481849; this version posted March 3, 2022. The copyright holder for this preprint available under aCC-BY-NC-ND 4.0 International license.

$$
\text { PCBrainAge }=\text { Age }+ \text { PropNeurons }+(1 \mid \text { Region }) \quad \text { (eq. 1) }
$$

We then related age acceleration in each region to AD neuropathology, clinical and pathologic diagnoses, and APOE $\varepsilon 4$ carrier status. To account for multiple comparisons, we used a p-value adjustment according to a Benjamini Hochberg procedure from a Kruskal Wallis test of nonparametric mean differences (Table 2). Age acceleration in prefrontal cortex and striatum were both associated with AD neuropathology and premortem clinical diagnosis. Age acceleration in the striatum was also higher in accordance with APOE $\varepsilon 4$ carrier status (Figure 5). It is important to note that the dataset used here is a subset of the test dataset used in Figure 3 (See Figure S5). The associations here are weaker compared to Figure 3 likely due to the reduced power, as this dataset contains fewer samples. This effect is magnified when comparing multiple brain region samples for each individual which increases complexity of comparisons without an increase in the number of individuals.

The cerebellum has long been characterized as relatively spared in $\mathrm{AD}$, though this has been challenged recently [43]. Interestingly, the cerebellum ages slowly according to the multiple epigenetic clocks, and existing epigenetic clocks do not show correlations between cerebellum age acceleration and AD neuropathology [42] (Figure S4). These other clocks were not trained in brain tissue, so it remains plausible that brain-or even cerebellum specific — epigenetic aging signatures are correlated with AD. However, we found that PCBrainAge acceleration in cerebellum is not significantly correlated with AD diagnosis, neuropathology, or APOE $\varepsilon 4$ carrier status (Figure 5). Thus, PCBrainAge validates prior reports that the cerebellum's methylation age diverges from that of other brain regions reflecting its distinctive biology in AD.

Taken together, PCBrainAge demonstrates associations with AD neuropathology, diagnosis, and APOE $\varepsilon 4$ carrier status in three regions affected by $\mathrm{AD}$ (DLPFC, PFC, and striatum) but not in a region that may be relatively spared in AD (cerebellum). Furthermore, PCBrainAge is applicable in multiple brain regions despite being trained specifically in DLPFC.

\section{Discussion}

While epigenetic clocks trained in blood, or multiple tissues, can reflect age in brain tissue [45], biomarkers trained specifically for the brain may more accurately capture its aging trends. Clocks trained in peripheral tissue can reflect postmortem AD pathology when applied to brain DNAm data [46]. However, with 
bioRxiv preprint doi: https://doi.org/10.1101/2022.02.28.481849; this version posted March 3, 2022. The copyright holder for this preprint available under aCC-BY-NC-ND 4.0 International license.

the exception of the PhenoAge clock [23], the acceleration captured does not typically demonstrate significant association with $\mathrm{AD}$ dementia status, despite clear correlations with neuropathologically mediated cognitive decline [46]. This may reflect the intermediate complexity between molecular pathological change and higher order cognitive changes [reviewed in 45]. However, blood or pan-tissue trained clocks may not adequately capture brain aging, due to the brain's unique methylation profile [48-50], extreme diversity of specialized neuronal [51] and glial [52] cell types, and distinct developmental patterns [53]. Thus, a methylation-based predictor of age in the brain is useful for studying age-related patterns of change in neurodegenerative disease at its source.

Prior work has been done to develop methylation-based predictors of age in the brain in humans [24] and

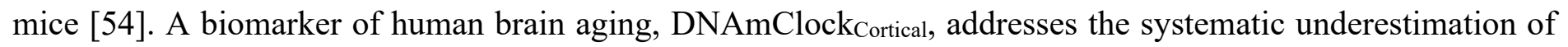
age in older adults when predicting brain age by existing clocks. While DNAmClock cortical $_{\text {can }}$ achieve nearperfect age correlation in brain tissue, this was not the goal of the present model. The lower correlation of PCBrainAge in the test datasets, as depicted in Figure 3, carries important biological signal. While the present clock does not achieve the degree of correlation of clock age and sample age at death found by DNAmClock $\mathrm{cortical}_{\text {, }}$ PCBrainAge's utility lies in the robust link between an individual's PCBrainAge residual (age acceleration), and pathological characteristics of AD. Beyond this, generation of PCBrainAge employed a novel methodology that allowed few samples for adequate training and was shown to reduce technical noise, thereby improving confidence in biological interpretation of the reported age residuals. Reduction of technical noise in this manner has also been hypothesized to reduce the sample size needed to train a robust epigenetic clock model [28], addressing the marked scarcity of brain tissue in comparison to blood DNAm. Furthermore, PCBrainAge demonstrates applicability across brain regions.

While a connection between DNA methylation and AD neuropathology has been a previously discussed possibility $[47,55]$, the current work also demonstrates a connection between patterns of DNA methylation change and higher order changes like those to cognition, and significant genetic differences like APOE $\varepsilon 4$ status. The acceleration predicted by PCBrainAge is correlated with clinical AD dementia, and pathologic AD, outperforms sex specific and pooled sex models in both males and females, and can be used across multiple cortical and noncortical brain regions. PCBrainAge is also significantly associated with APOE $\varepsilon 4$ status (see Figure $3 F$ ), which 
bioRxiv preprint doi: https://doi.org/10.1101/2022.02.28.481849; this version posted March 3, 2022. The copyright holder for this preprint

(which was not certified by peer review) is the author/funder, who has granted bioRxiv a license to display the preprint in perpetuity. It is made available under aCC-BY-NC-ND 4.0 International license.

has not been previously shown with existing blood-based clocks. With APOE $\varepsilon 4$ carriers exhibiting PCBrainAge acceleration over their non-carrier counterparts, PCBrainAge is consistent with observations that this genotype significantly increases risk in an age-related manner [56]. PCBrainAge can also detect the interaction between APOE status and cognitive diagnoses, given that APOE carriers show acceleration regardless of diagnosis, while noncarriers with $\mathrm{AD}$ show distinct acceleration versus those who appear cognitively normal. One limitation, however, is that our dataset shows an enrichment of APOE $\varepsilon 4$ carriers with MCI and dementia over cognitively normal counterparts. Regardless, this may reflect APOE $\& 4$ carriers' increased neuropathological burden [57,58], while suggesting that APOE carriers may not be aggressively predisposed to higher order cognitive changes.

PCBrainAge can predict age across multiple brain regions while also capturing heterogeneity relevant to $\mathrm{AD}$ in that region. The degree of correlation recapitulates previously described differences in the rate of aging of brain samples [40,42]. DLPFC, PFC, and ST are routinely impacted by AD pathology, unlike cerebellum [5961]. We found that PCBrainAge acceleration is associated with $\mathrm{AD}$ pathology and dementia status in these regions. This signal is slightly more robust in ST, where age correlation is stronger and separation between pathological groups is more distinct. It has been well characterized that tau and amyloid impact brain regions at varying times and to varying degrees. Further investigation is necessary as to whether a model of epigenetic brain aging reflects a relationship between pathological temporality and epigenetic alterations.

In the cerebellum, PCBrainAge recapitulates aging deceleration reported in previous studies [42]. Here we also show that age acceleration of cerebellum lacks correlation with Alzheimer's pathology and disease status. The slower predicted rate of aging in CBM conforms to expectations that CBM aging and its relationship to AD are drastically different from other brain regions. Without knowing the causal direction for the link between age related $5 \mathrm{mC}$ changes and $\mathrm{AD}$ pathology, the mechanisms for this relationship remain unclear. There is some evidence that amyloid beta can reduce methyltransferase activity resulting in global hypomethylation, and cerebellum is relatively spared of amyloid pathology until very late in the disease [62]. Future studies should investigate these mechanisms.

PCBrainAge is a promising predictor of regional brain aging, with demonstrated recapitulation of known aging trends in multiple brain regions. However, beyond tracking the relative aging of various brain regions, it 
bioRxiv preprint doi: https://doi.org/10.1101/2022.02.28.481849; this version posted March 3, 2022. The copyright holder for this preprint (which was not certified by peer review) is the author/funder, who has granted bioRxiv a license to display the preprint in perpetuity. It is made available under aCC-BY-NC-ND 4.0 International license.

can assess meaningful age-acceleration, or pathological aging. This pathological age acceleration is further correlated to AD neuropathology, clinical AD diagnosis, and APOE $\varepsilon 4$ carrier status. PCBrainAge may aid in future investigations linking heterogeneity in the aging process to AD risk and individual resilience.

\section{Methods}

\section{Selection of Available DNA methylation Data}

DNA methylation data was acquired from multiple sources (Table S1). The training data was accessed from the Gene Expression Omnibus (GSE74193) [30] as the age range was much wider than in the Alzheimer's Cohort studied: This has the important effect of increasing the ratio of the range of the variable of interest (age) versus the signal (DNAm) noise due to technical error, biological heterogeneity, and the effect of diseases. All sample methylation $\beta$ values were generated from the dorsolateral prefrontal cortex (DLPFC) using the Infinium HumanMethylation450K Beadchip (Illumina, San Diego CA, USA) and were used as collected, normalized, and reported by the original authors [30]. Samples under the age of 20 from the original GEO dataset were excluded as it has been shown that development typically has a different aging regime when considering epigenetic clocks $[22,63]$.

For assessment of PCBrainAge in the context of neurodegeneration and AD, we used the previously collected synapse dataset (syn5850422) [35] which generated Illumina 450K methylation data in postmortem DLPFC of participants in the Religious Orders Study and the Rush Memory \& Aging Project (ROSMAP) [64]. Methylation $\beta$ values were used as originally collected, normalized, and reported by the original authors [65]. Samples were excluded if their clinical diagnosis value was a non-AD primary cause of dementia [66]. Use of these samples would introduce significant uncertainty beyond the scope of the current work. Clinical diagnoses were dementia, mild cognitive impairment, and no cognitive impairment, and Alzheimer's dementia proximate to death $(\mathrm{n}=700)$ [67]. Neuropathologic data included CERAD, Braak, and pathologic AD by NIA-Reagan [68]. AD neuropathology was previously generated for this dataset: Neuritic and diffuse plaques, and neurofibrillary tangles were estimated using count data from silver stain; PHFtau tangle density and $\beta$-Amyloid load were each estimated using molecularly specific immunohistochemistry [69].

\section{Generation of Multi-Region Brain Methylation Data}

Novel collection of multi-region brain 5'-cytosine DNA methylation data was performed for the current work. This data was collected from frozen brain tissue samples obtained from Rush University's Religious Orders Study and Rush Memory and Aging Project (ROSMAP) [64]. Frozen tissue was isolated in 349 individuals across three brain regions: Brodmann Areas 10 (prefrontal cortex), 22 (striatum), and cerebellum.

Bulk genomic DNA was extracted from each tissue sample using the Chemagic DNA Tissue100 H24 prefilling VD1208504.che protocol (Perkin Elmer Ref\# CMG-1207). In brief, tissue was lysed overnight at 56 degrees in 1mL Chemagic Lysis buffer and 50uL Proteinase K. Samples were treated with 80uL of RNASE A @ 4mg/uL (AmericanBio Ref\# AB12023-00100) for 10 minutes at 56C. Lysis was then transferred to a deep well plate and the extraction performed via the Perkin Elmer Chemagic 360 extraction instrument. Samples were centrifuged at 13000RPM for 1 minute, placed on a magnet and transferred to final $1.5 \mathrm{~mL}$ 
bioRxiv preprint doi: https://doi.org/10.1101/2022.02.28.481849; this version posted March 3, 2022. The copyright holder for this preprint (which was not certified by peer review) is the author/funder, who has granted bioRxiv a license to display the preprint in perpetuity. It is made available under aCC-BY-NC-ND 4.0 International license.

Eppendorf tubes. 25-50 mg of extracted DNA per sample was then used according to the manufacturer's protocol on the Illumina Methylation EPIC array at the Yale Center for Genome Analysis (YCGA) with sample randomization on each array to mitigate batch effects.

The raw .idat files of bisulfite-converted single-CpG resolution of methylation were processed to obtain $\beta$ values through ratios of probe intensities, according to standard methods. Using the $\mathrm{R}$ 'minfi' package [70], Noob normalization was performed on $\beta$ values. For more information, the method used herein was derived from a prior publication [71]. The raw (syn23633756) and normalized beta value (syn23633757) data have been deposited to Synapse (Sage Bionetworks, Seattle, WA).

The sample phenotype data was provided as previously generated by the Rush University Alzheimer's Disease Center, and in accordance with prior publications: Individuals' clinical diagnoses [67] and neuropathologic data [68] were annotated as in the test dataset.

CpG Selection

5'-cytosine DNA methylation was collected on two different arrays across datasets: The 450K and EPIC arrays. Therefore, DNAm was limited to only the intersection of sites between the two arrays. Further, CpGs located on sex chromosomes, as indicated in the Illumina 450K array manifest were excluded. This resulted in retention of 357,852 CpGs.

\section{Model Training}

Singular vector decomposition was implemented using the prcomp function in the R stats package (v3.6.1). Detailed methods for training and principal component projection can be found in the methods of Higgins-Chen et al. [28]. In brief, centered principal component scores for individuals, understood as an individual's score based upon their $\mathrm{CpG} \beta$ values undergoing a rotation according to the rotation matrix, are used as inputs for an elastic net regression to predict age at death. That is, rather than using the original beta values for a given individual's CpGs, the left singular vectors (PCs) are used instead (excluding only the last PC). Elastic net regression was performed using the glmnet package in R, according to a mixing parameter $(\boldsymbol{\alpha})$ of 0.5 , utilizing equal parts LASSO and ridge regression with 10 -fold cross validation. All fit models were estimated using penalization $(\lambda)$ corresponding to predicted minimal error. Training of the age predictor was performed thus in an unsupervised manner, and in a dataset without clinical AD individuals. The final PCBrainAge model, which constitutes the "core" model entailed retraining an elastic net model such that PCs were zeroed out if not one of the 15 core principal components which had some nonzero weight in the original three models.

\section{Estimation of Neuron Proportion}

Along with methylation data, publicly available dataset annotations provided sorted cell proportion estimates, or estimates of neuron and glia proportion calculated using the methylation-based Cell Epigenotype Specific Model (CETS) for R package [72]. In the novel, multi-region dataset, the CETS package was used to estimate the proportion of neurons in each brain region sample. 
bioRxiv preprint doi: https://doi.org/10.1101/2022.02.28.481849; this version posted March 3, 2022. The copyright holder for this preprint (which was not certified by peer review) is the author/funder, who has granted bioRxiv a license to display the preprint in perpetuity. It is made available under aCC-BY-NC-ND 4.0 International license.

All reported scatterplot and predictor of age at death correlations (and corresponding p-values) are the result of correlation tests between means according to the Pearson's product moment coefficient, presuming standard normal distributions. This is implemented using the $\mathrm{R}$ function cor.test from the stats package. Correlations with annotations of phenotype, as in Figure 2A-B are the result of implementing a biweight midcorrelation, a median-based comparison test that improves sensitivity to outliers. This was implemented using the bicor function of the WGCNA package in R.

The p-value reported for all barplots are the result of a Kruskal-Wallis Rank Sum Test, which is a nonparametric test of means. This did not require assumptions of normality, and was applied using the kruskal.test function in the R stats package. Error bars on all barplots represent a standard error of the mean, unless explicitly noted otherwise.

In all tables offering many independent p-value comparisons (Table 2,S2), adjustment of p-values were necessary. All adjusted p-values were reported following implementation of the Benjamini Hochberg procedure, and values $\mathrm{p}<0.05$ were considered significant.

Linear mixed effects (LME) models were used in the context of the multiregion data. This required implementation of the lmer function of the lme4 package in R [73]. LMEs were optimized according to a Nelder Mead optimizer, and were visualized using the sjPlot package. Generation of LMEs were done in a hypothesis driven manner as described in the results, and were compared to the marginal $\mathrm{R}^{2}$ of less complex models. Visualization of the model table was performed using sjPlot [74].

\section{Author Contributions}

KLT, AHC and MEL jointly conceived of the current project and contributed to the writing of the manuscript. KLT carried out the analysis with direct feedback and additional suggested analyses from AHC and MEL. CVD and AHC provided clinical perspectives for the current work. SH and MEL contributed background and experience to the conceptualization of the project. DAB and CG provided specimens for data collection, generated clinical, neuropathologic and DNAm data, and critically reviewed the manuscript.

\section{Acknowledgements}

We are grateful to participants in the Religious Orders Study \& the Rush Memory and Aging Project, without whom the data supporting the current work would not have been possible. We would also like to thank the NIA's Resilience-AD consortium for their support and feedback on this work.

\section{Conflicts of Interest}

MEL previously acted as a Scientific Advisor for, and received consulting fees from, Elysium Health, Inc. AHC received consulting fees from FOXO Technologies, Inc. for work unrelated to the present manuscript. 
bioRxiv preprint doi: https://doi.org/10.1101/2022.02 28.481849; this version posted March 3, 2022. The copyright holder for this preprint (which was not certified by peer review) is the author/funder, who has granted bioRxiv a license to display the preprint in perpetuity. It is made available under aCC-BY-NC-ND 4.0 International license.

NIA 1R01AG057912-01 (MEL), NIMH 2T32MH019961-21A1 (AHC), the Medical Informatics Fellowship

Program at the West Haven, CT Veterans Healthcare Administration (AHC), NIA 1F31AG074627-01 (KLT).

ROSMAP is supported by P30AG10161, P30AG72975, R01AG15819, R01AG17917, R01AG36042,

U01AG46152, and U01AG61356. ROSMAP data can be requested at https://www.radc.rush.edu. 
bioRxiv preprint doi: https://doi.org/10.1101/2022.02.28.481849; this version posted March 3, 2022. The copyright holder for this preprint (which was not certified by peer review) is the author/funder, who has granted bioRxiv a license to display the preprint in perpetuity. It is made available under aCC-BY-NC-ND 4.0 International license.

\section{References}

1. Hou Y, Dan X, Babbar M, Wei Y, Hasselbalch SG, Croteau DL, Bohr VA. Ageing as a risk factor for neurodegenerative disease. Nat Rev Neurol [Internet]. Springer US; 2019; 15: 565-81. Available from: http://dx.doi.org/10.1038/s41582-019-0244-7

2. Kerchner GA, Wyss-Coray T. The Role of Aging in Alzheimer's Disease. In: Sierra F, Kohanski R, editors. Advances in Geroscience [Internet]. Cham: Springer International Publishing; 2016. p. $197-227$. Available from: https://doi.org/10.1007/978-3-319-23246-1_7

3. 2020 Alzheimer's disease facts and figures. Alzheimer's Dement. 2020; 16: 391-460.

4. Takahashi K, Yamanaka S. Induction of Pluripotent Stem Cells from Mouse Embryonic and Adult Fibroblast Cultures by Defined Factors. 2006; 2: 663-76.

5. Ocampo A, Reddy P, Martinez-Redondo P, Platero-Luengo A, Hatanaka F, Hishida T, Li M, Lam D, Kurita M, Beyret E, Araoka T, Vazquez-Ferrer E, Donoso D, et al. In Vivo Amelioration of AgeAssociated Hallmarks by Partial Reprogramming. Cell. 2016; 167: 1719-1733.e12.

6. Zhang W, Qu J, Liu GH, Belmonte JCI. The ageing epigenome and its rejuvenation. Nature Reviews Molecular Cell Biology. Nature Research; 2020. p. 137-50.

7. Cheng J, North BJ, Zhang T, Dai X, Tao K, Guo J, Wei W. The emerging roles of protein homeostasisgoverning pathways in Alzheimer's disease. Aging Cell. 2018; 17.

8. Jansen WJ, Ossenkoppele R, Knol DL, Tijms BM, Scheltens P, Verhey FRJ, Visser PJ, Group ABS, Aalten P, Aarsland D, Alcolea D, Alexander M, Almdahl IS, et al. Prevalence of cerebral amyloid pathology in persons without dementia: a meta-analysis. JAMA [Internet]. 2015; 313: 1924-38. Available from: https://pubmed.ncbi.nlm.nih.gov/25988462

9. Harrison TM, Joie R La, Maass A, Baker SL, Swinnerton K, Fenton L, Mellinger TJ, Pham J, Miller BL, Rabinovici GD, William J. Longitudinal Tau Accumulation and Atrophy in Aging and Alzheimer Disease. 2020; 85: 229-40.

10. Haroutunian V, Hoffman LB, Beeri MS. Is there a neuropathology difference between mild cognitive impairment and dementia? Dialogues Clin Neurosci. 2009; 11: 171-9.

11. Hyman BT, Phelps CH, Beach TG, Bigio EH, Cairns NJ, Carrillo MC, Dickson DW, Duyckaerts C, 
bioRxiv preprint doi: https://doi.org/10.1101/2022.02.28.481849; this version posted March 3, 2022. The copyright holder for this preprint

(which was not certified by peer review) is the author/funder, who has granted bioRxiv a license to display the preprint in perpetuity. It is made available under aCC-BY-NC-ND 4.0 International license.

Frosch MP, Masliah E, Mirra SS, Nelson PT, Schneider JA, et al. National Institute on Aging-

Alzheimer's Association guidelines for the neuropathologic assessment of Alzheimer's disease.

Alzheimer's Dement. 2012; 8: 1-13.

12. Therriault J, Benedet AL, Pascoal TA, Mathotaarachchi S, Chamoun M, Savard M, Thomas E, Kang MS,

Lussier F, Tissot C, Parsons M, Qureshi MNI, Vitali P, et al. Association of Apolipoprotein e $€ 4$ with

Medial Temporal Tau Independent of Amyloid- $\beta$. JAMA Neurol. 2020; 77: 470-9.

13. Liu C-C, Zhao N, Fu Y, Wang N, Linares C, Tsai C-W, Bu G. ApoE4 Accelerates Early Seeding of Amyloid Pathology. Neuron [Internet]. 2017; 96: 1024-1032.e3. Available from:

https://pubmed.ncbi.nlm.nih.gov/29216449

14. Strittmatter WJ, Saunders AM, Schmechel D, Pericak-Vance M, Enghild J, Salvesen GS, Roses AD. Apolipoprotein E: high-avidity binding to beta-amyloid and increased frequency of type 4 allele in lateonset familial Alzheimer disease. Proc Natl Acad Sci [Internet]. 1993; 90: 1977 LP - 1981. Available from: http://www.pnas.org/content/90/5/1977.abstract

15. Mahley RW, Rall SC. Apolipoprotein E: Far more than a lipid transport protein. Annu Rev Genomics Hum Genet. 2000; 1: 507-37.

16. Bennet AM, Di Angelantonio E, Ye Z, Wensley F, Dahlin A, Ahlbom A, Keavney B, Collins R, Wiman B, De Faire U, Danesh J. Association of apolipoprotein e genotypes with lipid levels and coronary risk. J Am Med Assoc. 2007; 298: 1300-11.

17. Kulminski AM, Culminskaya I, Ukraintseva S V., Arbeev KG, Arbeeva L, Wu D, Akushevich I, Land $\mathrm{KC}$, Yashin AI. Trade-off in the effects of the apolipoprotein E polymorphism on the ages at onset of CVD and cancer influences human lifespan. Aging Cell [Internet]. 2011; 10: 533-41. Available from: https://www.ncbi.nlm.nih.gov/pmc/articles/PMC3624763/pdf/nihms412728.pdf

18. Ewbank DC. The APOE Gene and Differences in Life Expectancy in Europe. Journals Gerontol - Ser A Biol Sci Med Sci. 2004; 59: 16-20.

19. Sanchez-Mut J V., Gräff J. Epigenetic alterations in Alzheimer's disease. Front Behav Neurosci. 2015; 9: $1-17$. 
20. Nativio R, Lan Y, Donahue G, Sidoli S, Berson A, Srinivasan AR, Shcherbakova O, Amlie-Wolf A, Nie

J, Cui X, He C, Wang LS, Garcia BA, et al. An integrated multi-omics approach identifies epigenetic alterations associated with Alzheimer's disease. Nat Genet [Internet]. Springer US; 2020; 52: $1024-35$.

Available from: http://dx.doi.org/10.1038/s41588-020-0696-0

21. Simpson DJ, Chandra T. Epigenetic age prediction. Aging Cell. 2021; 20: 1-20.

22. Horvath S. DNA methylation age of human tissues and cell types. Genome Biol [Internet]. 2013; 14:

3156. Available from: https://doi.org/10.1186/gb-2013-14-10-r115

23. Levine ME, Lu AT, Quach A, Chen BH, Assimes TL, Bandinelli S, Hou L, Baccarelli AA, Stewart JD, Li Y, Whitsel EA, Wilson JG, Reiner1 AP, et al. An epigenetic biomarker of aging for lifespan and healthspan. Aging (Albany NY) [Internet]. 2018; 10: 573-91. Available from:

https://www.scopus.com/inward/record.uri?eid=2-s2.0-

85046851006\&doi=10.18632\%2Faging.101414\&partnerID=40\&md5=5c29679a6b886d9fcd95769e1b0f 2119

24. Shireby GL, Davies JP, Francis PT, Burrage J, Walker EM, Neilson GWA, Dahir A, Thomas AJ, Love S, Smith RG, Lunnon K, Kumari M, Schalkwyk LC, et al. Recalibrating the epigenetic clock: implications for assessing biological age in the human cortex. Brain. 2020; : 1-13.

25. Grodstein F, Lemos B, Yu L, Klein HU, Iatrou A, Buchman AS, Shireby GL, Mill J, Schneider JA, De Jager PL, Bennett DA. The association of epigenetic clocks in brain tissue with brain pathologies and common aging phenotypes. Neurobiol Dis [Internet]. Elsevier Inc.; 2021; 157: 105428. Available from: https://doi.org/10.1016/j.nbd.2021.105428

26. Grothe MJ, Barthel H, Sepulcre J, Dyrba M, Sabri O, Teipel SJ. In vivo staging of regional amyloid deposition From the German Center for Neurodegenerative Diseases (DZNE) (M. 2017; 0: 2031-8.

27. Braak H, Braak E. Staging of Alzheimer's Disease-Related Neurofibrillary Changes. Neurobiol Aging. $1995 ; 16: 271-84$.

28. Higgins-chen AT, Thrush KL, Wang Y, Kuo P-L, Wang M, Minteer CJ, Moore AZ, Bandinelli S, Vinkers CH, Vermetten E, Rutten BPF, Geuze E, Okhuijsen-Pfeifer C, et al. A computational solution 
bioRxiv preprint doi: https://doi.org/10.1101/2022.02.28.481849; this version posted March 3, 2022. The copyright holder for this preprint

(which was not certified by peer review) is the author/funder, who has granted bioRxiv a license to display the preprint in perpetuity. It is made available under aCC-BY-NC-ND 4.0 International license.

for bolstering reliability of epigenetic clocks: Implications for clinical trials and longitudinal tracking. bioRxiv. 2021; .

29. Barrett T, Wilhite SE, Ledoux P, Evangelista C, Kim IF, Tomashevsky M, Marshall KA, Phillippy KH, Sherman PM, Holko M, Yefanov A, Lee H, Zhang N, et al. NCBI GEO: Archive for functional genomics data sets - Update. Nucleic Acids Res. 2013; 41: 991-5.

30. Jaffe AE, Gao Y, Deep-Soboslay A, Tao R, Hyde TM, Weinberger DR, Kleinman JE. Mapping DNA methylation across development, genotype and schizophrenia in the human frontal cortex. Nat Neurosci. Nature Publishing Group; 2016; 19: 40-7.

31. Higgins-chen AT, Boks MP, Vinkers CH, Kahn RS, Levine ME. Schizophrenia and Epigenetic Aging Biomarkers: Increased Mortality, Reduced Cancer Risk, and Unique Clozapine Effects. 2020; 88: 224 35.

32. McKinney BC, Lin H, Ding Y, Lewis DA, Sweet RA. DNA methylation age is not accelerated in brain or blood of subjects with schizophrenia. Schizophr Res. 2018; 196: 39-44.

33. Austad SN, Bartke A. Sex Differences in Longevity and in Responses to Anti-Aging Interventions : A Mini-Review. 2016; 1170: 40-6.

34. Fisher DW, Bennett DA, Dong H. Sexual dimorphism in predisposition to Alzheimer's disease. Neurobiol Aging [Internet]. 2018/04/17. 2018; 70: 308-24. Available from: https://pubmed.ncbi.nlm.nih.gov/29754747

35. De Jager PL, Ma Y, McCabe C, Xu J, Vardarajan BN, Felsky D, Klein HU, White CC, Peters MA, Lodgson B, Nejad P, Tang A, Mangravite LM, et al. Data descriptor: A multi-omic atlas of the human frontal cortex for aging and Alzheimer's disease research. Sci Data. 2018; 5: 1-13.

36. Chen B Sen, Li CW. Constructing an integrated genetic and epigenetic cellular network for whole cellular mechanism using high-throughput next-generation sequencing data. BMC Syst Biol [Internet]. BMC Systems Biology; 2016; 10: 1-18. Available from: http://dx.doi.org/10.1186/s12918-016-0256-5 37. Field AE, Robertson NA, Wang T, Havas A, Ideker T, Adams PD. DNA Methylation Clocks in Aging: Categories, Causes, and Consequences. Mol Cell [Internet]. 2018; 71: 882-95. Available from: 
https://pubmed.ncbi.nlm.nih.gov/30241605

38. Sando SB, Melquist S, Cannon A, Hutton ML, Sletvold O, Saltvedt I, White LR, Lydersen S, Aasly JO. APOE epsilon 4 lowers age at onset and is a high risk factor for Alzheimer's disease; a case control study from central Norway. BMC Neurol [Internet]. BioMed Central; 2008; 8: 9. Available from:

https://pubmed.ncbi.nlm.nih.gov/18416843

39. Peters R. Ageing and the brain. Postgrad Med J [Internet]. BMJ Group; 2006; 82: 84-8. Available from: https://pubmed.ncbi.nlm.nih.gov/16461469

40. Liu Z, Leung D, Thrush K, Zhao W, Ratliff S, Tanaka T, Schmitz LL, Smith JA, Ferrucci L, Levine ME. Underlying features of epigenetic aging clocks in vivo and in vitro. Aging Cell. 2020; : 1-11.

41. Hane FT, Lee BY, Leonenko Z. Recent Progress in Alzheimer's Disease Research, Part 1: Pathology. J Alzheimer's Dis. 2017; 57: 1-28.

42. Horvath S, Mah V, Lu AT, Woo JS, Choi O-W, Jasinska AJ, Riancho JA, Tung S, Coles NS, Braun J, Vinters H V, Coles LS. The cerebellum ages slowly according to the epigenetic clock. Aging (Albany NY) [Internet]. Impact Journals LLC; 2015; 7: 294-306. Available from:

https://pubmed.ncbi.nlm.nih.gov/26000617

43. Jacobs HIL, Hopkins DA, Mayrhofer HC, Bruner E, Van Leeuwen FW, Raaijmakers W, Schmahmann JD. The cerebellum in Alzheimer's disease: Evaluating its role in cognitive decline. Brain. 2018; 141: $37-47$.

44. Hoxha E, Lippiello P, Zurlo F, Balbo I, Santamaria R, Tempia F, Miniaci MC. The emerging role of altered cerebellar synaptic processing in Alzheimer's disease. Front Aging Neurosci. 2018; 10: 1-9.

45. Horvath S, Raj K. DNA methylation-based biomarkers and the epigenetic clock theory of ageing. Nat Rev Genet [Internet]. Springer US; 2018; 19: 371-84. Available from: http://dx.doi.org/10.1038/s41576018-0004-3

46. Levine ME, Lu AT, Bennett DA, Horvath S. Epigenetic age of the pre-frontal cortex is associated with neuritic plaques, amyloid load, and Alzheimer's disease related cognitive functioning. Aging (Albany NY). 2015; 7: 1198-211. 
bioRxiv preprint doi: https://doi.org/10.1101/2022.02.28.481849; this version posted March 3, 2022. The copyright holder for this preprint (which was not certified by peer review) is the author/funder, who has granted bioRxiv a license to display the preprint in perpetuity. It is made available under aCC-BY-NC-ND 4.0 International license.

47. Yokoyama AS, Rutledge JC, Medici V. DNA methylation alterations in Alzheimer's disease. Environ Epigenetics. 2017; 3: 1-11.

48. Kinde B, Gabel HW, Gilbert CS, Griffith EC, Greenberg ME. Reading the unique DNA methylation landscape of the brain: Non-CpG methylation, hydroxymethylation, and MeCP2. Proc Natl Acad Sci U S A. $2015 ; 112: 6800-6$.

49. Spiers H, Hannon E, Schalkwyk LC, Bray NJ, Mill J. 5-Hydroxymethylcytosine Is Highly Dynamic Across Human Fetal Brain Development. BMC Genomics. BMC Genomics; 2017; 18: 1-14.

50. Kozlenkov A, Li J, Apontes P, Hurd YL, Byne WM, Koonin E V., Wegner M, Mukamel EA, Dracheva S. A unique role for DNA (hydroxy)methylation in epigenetic regulation of human inhibitory neurons. Sci Adv. 2018; 4.

51. Zeng H, Sanes JR. Neuronal cell-type classification: Challenges, opportunities and the path forward. Nat Rev Neurosci [Internet]. Nature Publishing Group; 2017; 18: 530-46. Available from: http://dx.doi.org/10.1038/nrn.2017.85

52. Mizeracka K, Heiman MG. The many glia of a tiny nematode: Studying glial diversity using Caenorhabditis elegans. Wiley Interdiscip Rev Dev Biol. 2015; 4: 151-60.

53. Stiles J, Jernigan TL. The basics of brain development. Neuropsychol Rev. 2010; 20: 327-48.

54. Coninx E, Chew YC, Yang X, Guo W, Coolkens A, Baatout S, Moons L, Verslegers M, Quintens R. Hippocampal and cortical tissue-specific epigenetic clocks indicate an increased epigenetic age in a mouse model for Alzheimer's disease. Aging (Albany NY). 2020; 12: 20817-34.

55. Altuna M, Urdánoz-Casado A, Sánchez-Ruiz De Gordoa J, Zelaya M V., Labarga A, Lepesant JMJ, Roldán M, Blanco-Luquin I, Perdones Á, Larumbe R, Jericó I, Echavarri C, Méndez-López I, et al. DNA methylation signature of human hippocampus in Alzheimer's disease is linked to neurogenesis. Clin Epigenetics. Clinical Epigenetics; 2019; 11: 1-16.

56. Saddiki H, Fayosse A, Cognat E, Sabia S, Engelborghs S, Wallon D, Alexopoulos P, Blennow K, Zetterberg H, Parnetti L, Zerr I, Hermann P, Gabelle A, et al. Age and the association between apolipoprotein E genotype and Alzheimer disease: a cerebrospinal fluid biomarker-based case-control 
study. PLoS Med. 2020; 17: 1-20.

57. Lim YY, Mormino EC, Initiative F the ADN. Association Between Apolipoprotein E $\varepsilon 2$ vs $\varepsilon 4$, Age, and $\beta$-Amyloid in Adults Without Cognitive Impairment. Neurology [Internet]. 2017; 89: 1028 LP - 1034.

Available from: http://n.neurology.org/content/89/10/1028.abstract

58. Baek MS, Cho H, Lee HS, Lee JH, Ryu YH, Lyoo CH. Effect of APOE $\varepsilon 4$ genotype on amyloid- $\beta$ and tau accumulation in Alzheimer's disease. Alzheimer's Res Ther. Alzheimer's Research \& Therapy; 2020;

12: $1-12$.

59. DeTure MA, Dickson DW. The neuropathological diagnosis of Alzheimer's disease. Mol Neurodegener. Molecular Neurodegeneration; 2019; 14: 1-18.

60. Braak H, Braak E. Frequency of stages of Alzheimer-related lesions in different age categories. Neurobiol Aging. 1997; 18: 351-7.

61. Thal DR, Rüb U, Orantes M, Braak H. Phases of A $\beta$-deposition in the human brain and its relevance for the development of AD. Neurology. 2002; 58: 1791-800.

62. Mastroeni D, Grover A, Delvaux E, Whiteside C, Coleman PD, Rogers J. Epigenetic changes in Alzheimer's disease: Decrements in DNA methylation. Neurobiol Aging [Internet]. Elsevier Inc.; 2010; 31: 2025-37. Available from: http://dx.doi.org/10.1016/j.neurobiolaging.2008.12.005

63. Snir S, Farrell C, Pellegrini M. Human epigenetic ageing is logarithmic with time across the entire lifespan. Epigenetics [Internet]. Taylor \& Francis; 2019; 14: 912-26. Available from: https://doi.org/10.1080/15592294.2019.1623634

64. Bennett DA, Buchman AS, Boyle PA, Barnes LL, Wilson RS, Schneider JA. Religious Orders Study and Rush Memory and Aging Project. J Alzheimer's Dis. 2018; 64: S161-89.

65. De Jager PL, Srivastava G, Lunnon K, Burgess J, Schalkwyk LC, Yu L, Eaton ML, Keenan BT, Ernst J, McCabe C, Tang A, Raj T, Replogle J, et al. Alzheimer's disease: Early alterations in brain DNA methylation at ANK1, BIN1, RHBDF2 and other loci. Nat Neurosci. Nature Publishing Group; 2014; 17 : 1156-63.

66. Schneider JA, Arvanitakis Z, Woojeong B, Bennett DA. Mixed brain pathologies account for most 
dementia cases in community-dwelling older persons. Neurology. 2007; 69: 2197-204.

67. Bennett DA, Wilson RS, Schneider JA, Evans DA, Beckett LA, Aggarwal NT, Barnes LL, Fox JH, Bach J. Natural history of mild cognitive impairment in older persons. Neurology. 2002; 59: 198-205.

68. Bennett DA, Schneider JA, Arvanitakis Z, Kelly JF, Aggarwal NT, Shah RC, Wilson RS.

Neuropathology of older persons without cognitive impairment from two community-based studies.

Neurology. 2006; 66: 1837-44.

69. Wilson RS, Arnold SE, Schneider JA, Tang Y, Bennett DA. The relationship between cerebral Alzheimer's disease pathology and odour identification in old age. J Neurol Neurosurg Psychiatry. 2007; 78: $30-5$.

70. Fortin JP, Triche TJ, Hansen KD. Preprocessing, normalization and integration of the Illumina HumanMethylationEPIC array with minfi. Bioinformatics. 2017; 33: 558-60.

71. Horvath S, Oshima J, Martin GM, Lu AT, Quach A, Cohen H, Felton S, Matsuyama M, Lowe D, Kabacik S, Wilson JG, Reiner AP, Maierhofer A, et al. Epigenetic clock for skin and blood cells applied to Hutchinson Gilford Progeria Syndrome and ex vivo studies. Aging (Albany NY). 2018; 10: 1758-75.

72. Guintivano J, Aryee MJ, Kaminsky ZA. A cell epigenotype specific model for the correction of brain cellular heterogeneity bias and its application to age, brain region and major depression. Epigenetics. 2013; 8: 290-302.

73. Bates D, Mächler M, Bolker B, Walker S. Fitting Linear Mixed-Effects Models Using lme4. J Stat Softw [Internet]. 2015; 67: 1-48. Available from: https://www.jstatsoft.org/index.php/jss/article/view/v067i01

74. Lüdecke D. sjPlot: Data Visualization for Statistics in Social Science R package version 2.8.10. 2021. 
bioRxiv preprint doi: https://doi.org/10.1101/2022.02.28.481849; this version posted March 3, 2022. The copyright holder for this preprint (which was not certified by peer review) is the author/funder, who has granted bioRxiv a license to display the preprint in perpetuity. It is made available under aCC-BY-NC-ND 4.0 International license.

\section{Manuscript Tables}

Table 1. Pearson's Correlation of Age by Sex with Model Age Predictions

\begin{tabular}{l|c:cc:cc}
\hline \multicolumn{1}{l}{ Model } & & Training Data & Core & Test Data & Core \\
\hline \multirow{2}{*}{ Both Sexes } & M & 0.99 & 0.94 & 0.61 & 0.65 \\
& F & 0.99 & 0.95 & 0.56 & 0.58 \\
\hline \multirow{2}{*}{ Male } & M & 0.98 & & 0.55 & \\
& F & 0.95 & 0.49 & \\
\hline \multirow{2}{*}{ Female } & M & 0.90 & & 0.61 & \\
& F & 0.97 & & 0.54 &
\end{tabular}

Table 2. Multi-Region PCBrainAge Acceleration's Correlates

to AD

\begin{tabular}{r|cccc}
\hline \multicolumn{1}{c}{ All } & PFC & ST & CBM \\
\hline CERAD & $1.1 \mathrm{E}-04^{*}$ & $6.3 \mathrm{E}-03^{*}$ & $6.3 \mathrm{E}-03^{*}$ & 0.13 \\
Braak & 0.087 & 0.25 & 0.067 & 0.15 \\
NIA-Reagan & $4.5 \mathrm{E}-04^{*}$ & $6.3 \mathrm{E}-03^{*}$ & $6.3 \mathrm{E}-03^{*}$ & 0.36 \\
Clinical Diagnosis & $6.3 \mathrm{E}-03^{*}$ & $6.3 \mathrm{E}-03^{*}$ & $4.7 \mathrm{E}-03^{*}$ & 0.13 \\
APOE & 0.24 & 0.52 & 0.076 & 0.68
\end{tabular}

* indicates a p-value $<0.05$ of Kruskal Wallis nonparametric tests of means across criterion groups, followed by adjustment according to the Benjamini Hochberg procedure when pooling all p-values in the table 
bioRxiv preprint doi: https://doi.org/10.1101/2022.02.28.481849; this version posted March 3, 2022. The copyright holder for this preprint (which was not certified by peer review) is the author/funder, who has granted bioRxiv a license to display the preprint in perpetuity. It is made available under aCC-BY-NC-ND 4.0 International license.

A

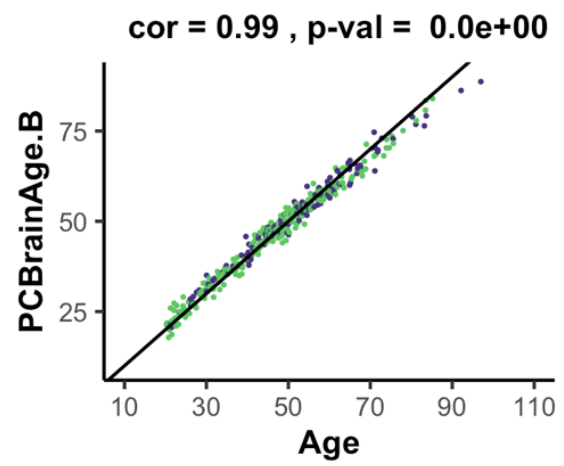

D
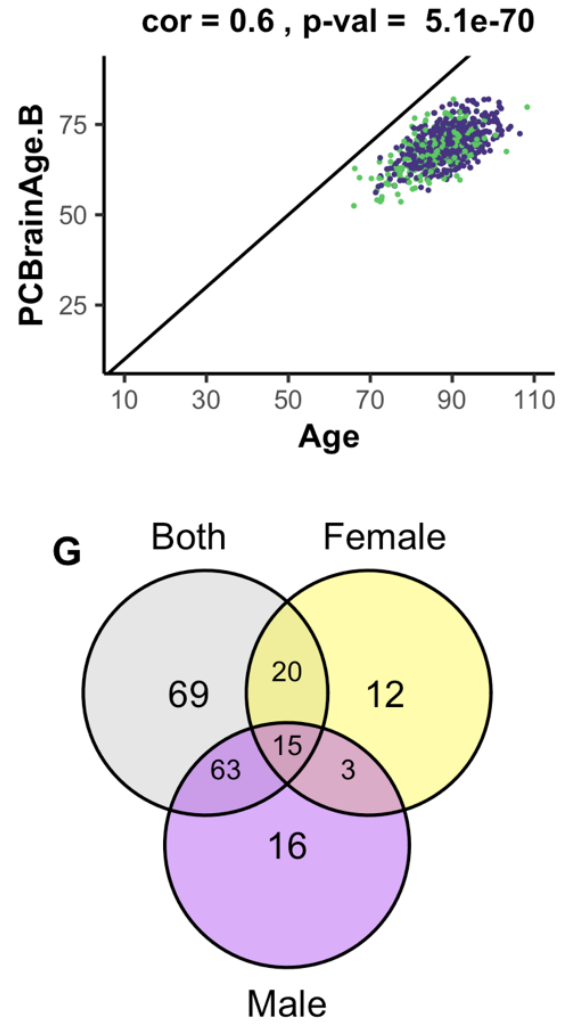

\section{Manuscript Figures}

\section{Training Data}

B

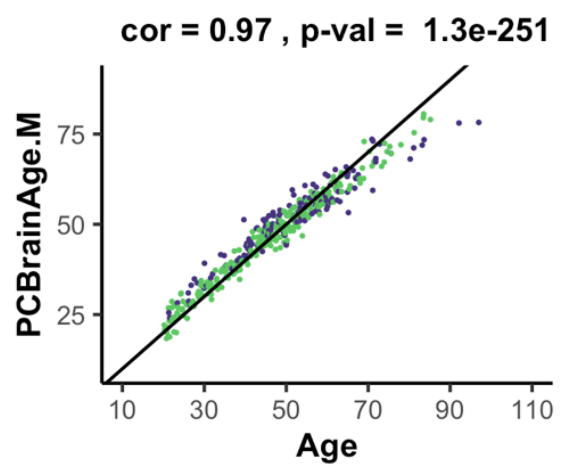

Testing Data
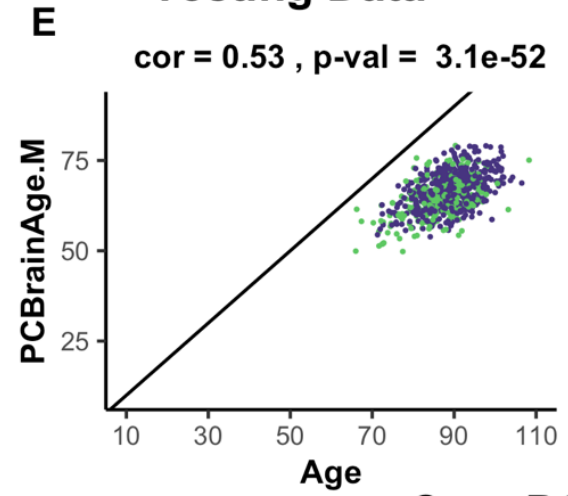

Core PC Model

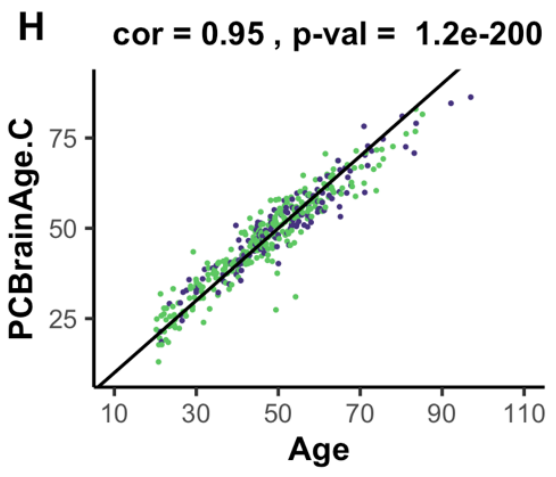

C

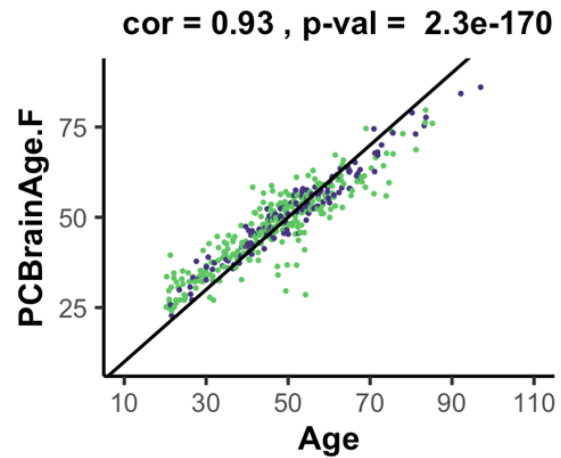

$\mathbf{F}$

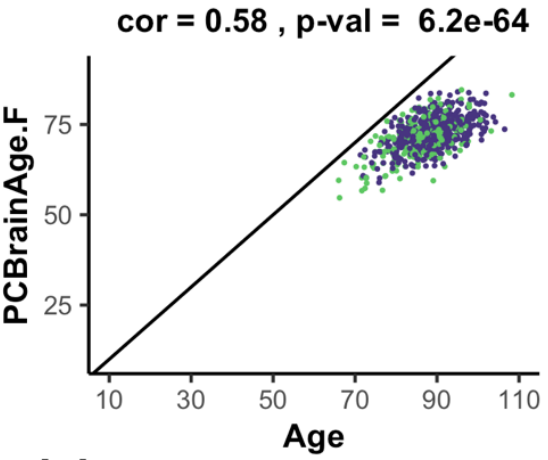

I $\quad$ cor $=0.62, p-v a l=3.3 e-76$

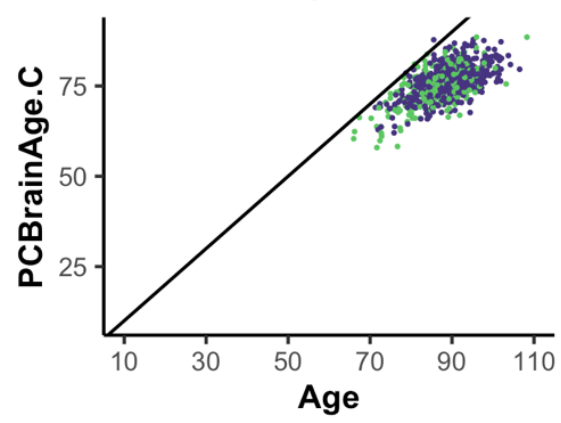

Figure 1: Training and testing of multiple iterations of PCBrainAge. Using the dataset from GSE74193, elastic net was used to predict age using principal component loadings in both sexes (A), only males (B), or only females (C). Here, we show the resultant predictions for each model in both females (purple) and males (green) regardless of training sex. Each model so trained is then predicted in all individuals from syn5850422 (D-F), regardless of sex or AD status. Each model selected a number of principal components to use for prediction, and we compared the selection of each model using a Venn diagram (G). Subsequent training of an elastic net model using only the 15 core principal components in both sexes is visualized $(\mathbf{H})$ and compared to performance in the test dataset (I). 
bioRxiv preprint doi: https://doi.org/10.1101/2022.02.28.481849; this version posted March 3, 2022. The copyright holder for this preprint (which was not certified by peer review) is the author/funder, who has granted bioRxiv a license to display the preprint in perpetuity. It is made available under aCC-BY-NC-ND 4.0 International license.

\section{A}

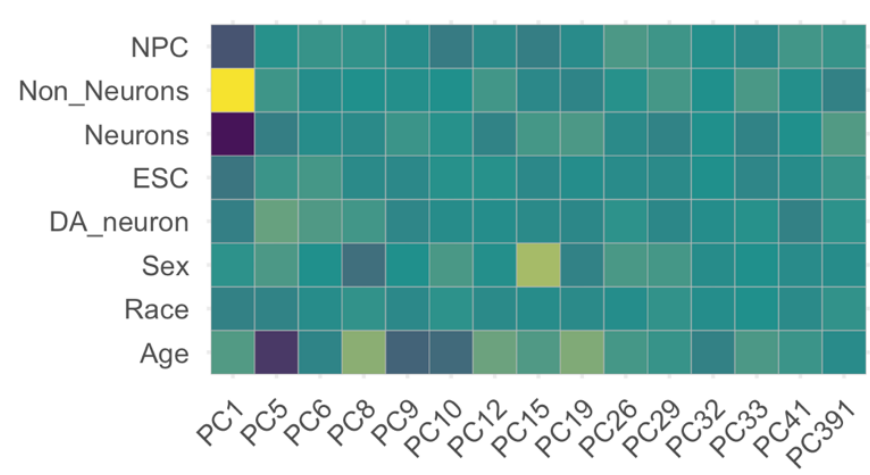

C

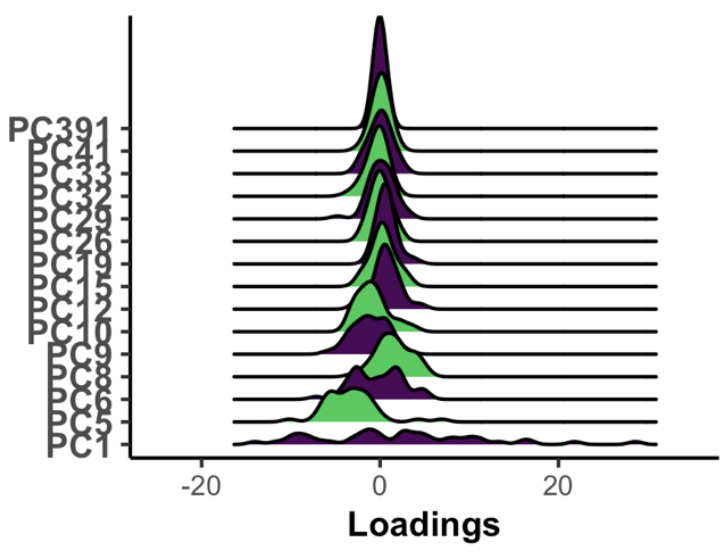

B

PHFTau Tangle Density Neurofibrillary Tangle Counts Diffuse Plaque Counts

Neuritic Plaque Counts

$$
\begin{array}{r}
\beta \text {-Amyloid Load } \\
\text { NIAReagan }
\end{array}
$$

Braak

Clinical Diagnosis APOE Study

Proportion of Neurons Sex
Age

D

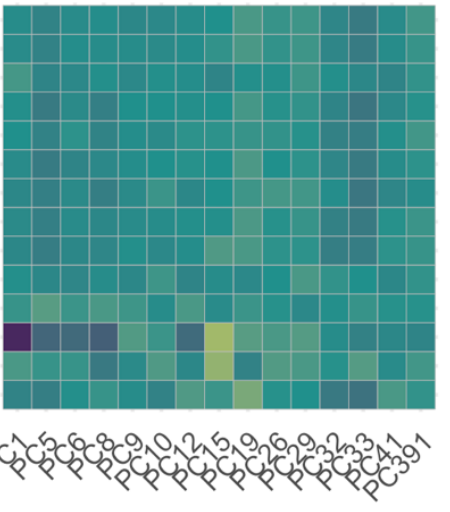

Bicor

0.5

0.0

$-0.5$

$-1.0$

Figure 2: Understanding Core Principal Component Composition. Principal component loadings for individuals in the training dataset were correlated using biweight midcorrelation (bicor) to selected author-provided phenotypic annotations (A). The same procedure was applied to the projected principal component loadings for all individuals in the test dataset, including those with and without Alzheimer's disease (B). To ensure that future correlations between age prediction and disease are not the result of unrealistic distortions in PC loadings following the prediction process, we used ridgeplots to visualize the distribution of loadings in each PC in age 65+ training individuals (C) and the test data (D). [Abbreviations: NPCs - neural progenitor cells; Cort. - cortical; ESCsembryonic stem cells; DA—dopaminergic; np—neuritic plaque] 




D

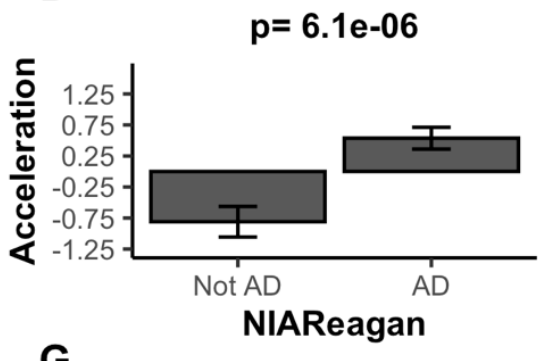

B



E

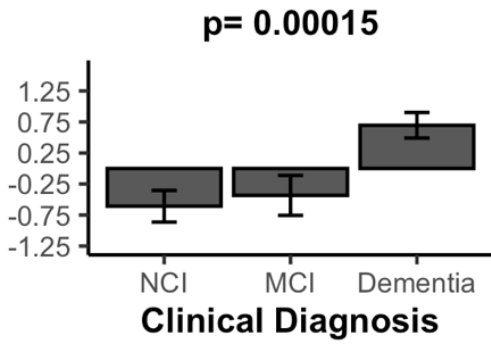

C

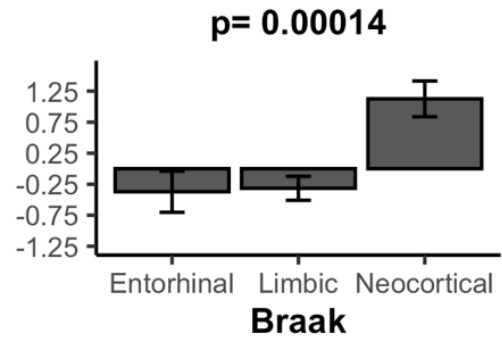

$\mathbf{F}$

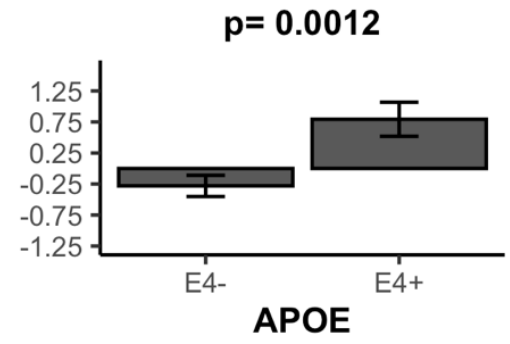

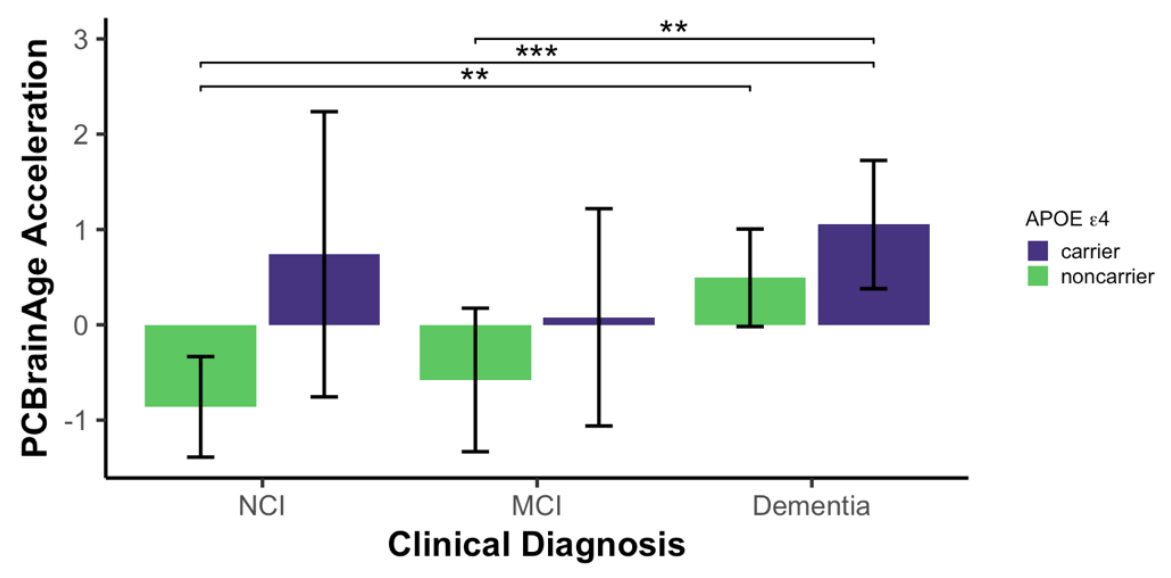

Figure 3: PCBrainAge Acceleration is Associated with Indications of AD. (A) PCBrainAge residuals following multiple correction were verified to remain orthogonal to age using a scatterplot with LOESS curves for males (green) and females (purple). PCBrainAge Acceleration was subsequently analyzed in the context of CERAD scores (B), Braak stages (C), NIA Reagan scores (D), the antemortem clinical diagnoses $(\mathbf{E})$, and the APOE $\varepsilon 4$ carrier status $(\mathbf{F})$ of each individual. P-values are the result of performing KruskalWallis tests of nonparametric means amongst the categorical groups. Error bars for 3B-3F depict 1 standard error. (G) Acceleration was further broken down into cognitive groups by APOE $\varepsilon 4$ carrier status for improved clarity. Error bars depict the $95 \%$ confidence interval. Significance levels based on $\mathrm{BH}$ adjusted $\mathrm{p}$ values are: $*<0.05, * *<0.01 ; * * *<0.001$. 
bioRxiv preprint doi: https://doi.org/10.1101/2022.02.28.481849; this version posted March 3, 2022. The copyright holder for this preprint (which was not certified by peer review) is the author/funder, who has granted bioRxiv a license to display the preprint in perpetuity. It is made available under aCC-BY-NC-ND 4.0 International license.

A
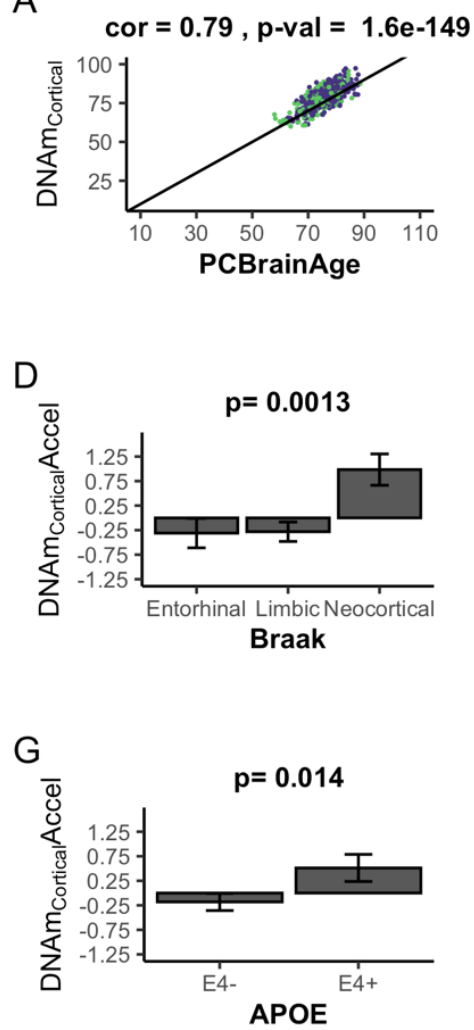

$B$

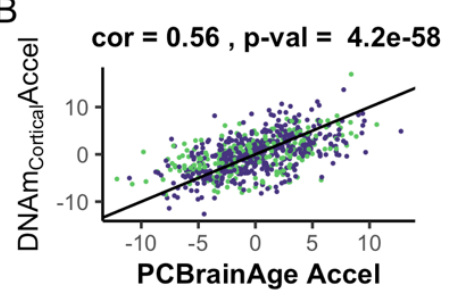

$\mathrm{E}$

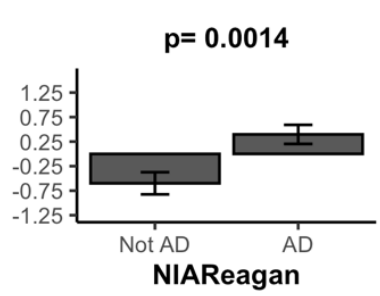

C



$\mathrm{F}$

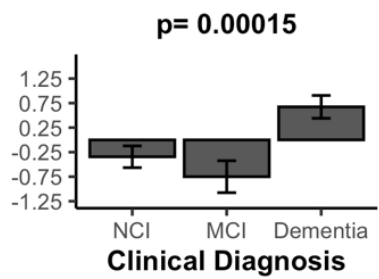

$\mathrm{H}$

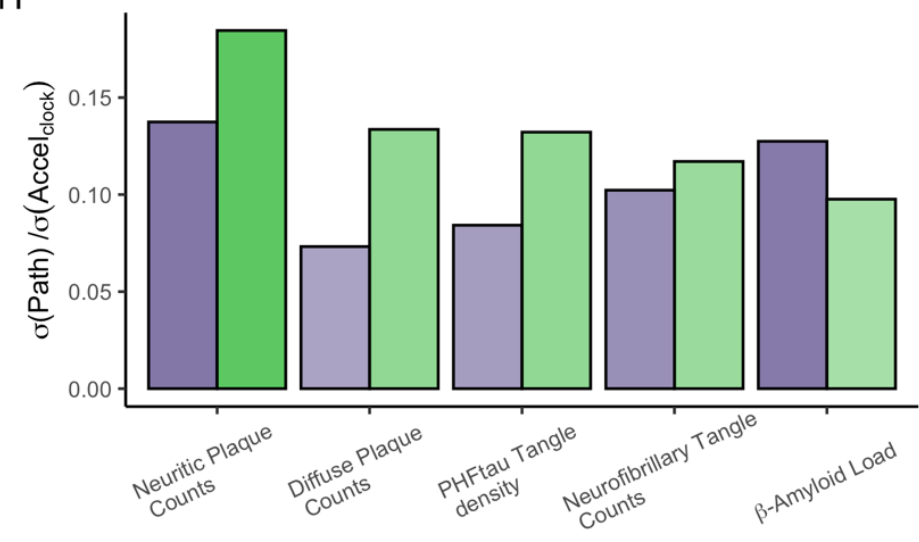

clock $\square$ DNAmCortical $\square$ PCBrainAge

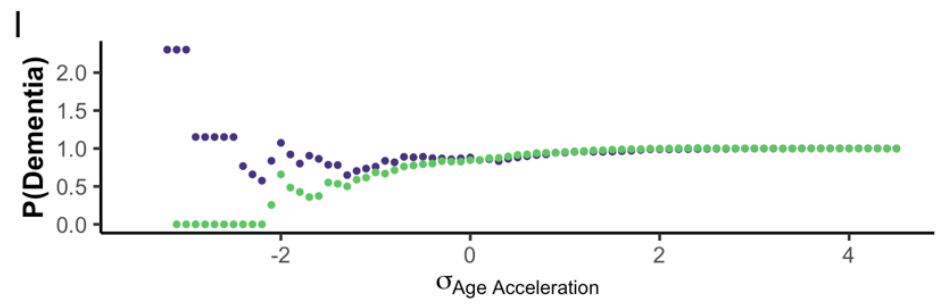

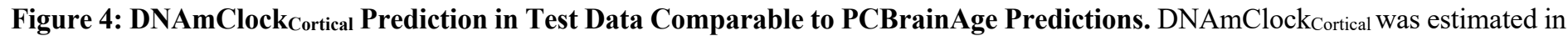
our test dataset, which is independent from it's original training. We find that DNAmClock $\mathrm{k}_{\text {cortical }}$ has moderate correlation with age at death (A), and agreement with PCBrainAge accelerations for the same individuals (B). While DNAmClock cortical does exhibit clear acceleration in (advanced) AD patients (C-E), demented patients $(\mathbf{F})$, and APOE 44 carriers $(\mathbf{G})$, the p-values of the separation between groups are slightly attenuated versus those of PCBrainAge (see Figure 3). The standard deviation of various AD pathological characteristics per clock standard deviation are compared for DNAmCortical (pink) and PCBrainAge (blue) (H). Given individuals less than or equal to a standard deviation of age acceleration for each clock, the probability of patients being diagnosed with dementia normalized to the total cohort probability is shown for each clock (I). 